\title{
Article
}

\section{Comparison of equipment used to measure shear properties in equine arena surfaces}

Lewis, Kate, Northrop, Alison J, Crook, Glen Martin, Mather, John, Martin, Jaime H, Holt, Danielle, Clayton, Hilary M, Roepstorff, Lars, Peterson, Michael and Hobbs, Sarah Jane

Available at http://clok.uclan.ac.uk/12452/

Lewis, Kate, Northrop, Alison J, Crook, Glen Martin, Mather, John, Martin, Jaime H, Holt, Danielle, Clayton, Hilary M, Roepstorff, Lars, Peterson, Michael et al (2015) Comparison of equipment used to measure shear properties in equine arena surfaces. Biosystems Engineering, 137 . pp. 43-54. ISSN 1537-5110

It is advisable to refer to the publisher's version if you intend to cite from the work. http://dx.doi.org/10.1016/j.biosystemseng.2015.07.006

For more information about UCLan's research in this area go to http://www.uclan.ac.uk/researchgroups/ and search for <name of research Group>.

For information about Research generally at UCLan please go to http://www.uclan.ac.uk/research/

All outputs in CLoK are protected by Intellectual Property Rights law, including Copyright law. Copyright, IPR and Moral Rights for the works on this site are retained by the individual authors and/or other copyright owners. Terms and conditions for use of this material are defined in the policies page.

\section{CLoK}

Central Lancashire online Knowledge www.clok.uclan.ac.uk

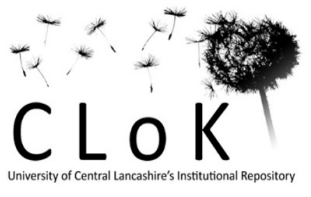




\section{Abstract}

2 The design of a novel apparatus, the Glen Withy torque tester (GWTT), for measuring

3 horizontal shear properties in equine sport surfaces is described. Previous research has

4 considered the effect of vertical loading on equine performance and injury but only limited

5 discussion has concerned the grip or horizontal motion of the hoof. The horizontal support of

6 the hoof by the surface must be sufficient to avoid excess slip without overloading the limb.

7 The GWTT measures the torque necessary to twist an artificial hoof that is being pushed into

8 the surface under a consistently applied vertical load. Its output was validated using a steel

9 surface, then was used to test two sand and fibre surfaces (waxed and non-waxed) through

10 rotations of $40-140^{\circ}$, and vertical loads of $156-980$ N. An Orono biomechanical surface

11 tester (OBST) measured longitudinal shear and vertical force, whilst a traction tester

12 measured rotational shear after being dropped onto the surfaces. A weak, but significant,

13 linear relationship was found between rotational shear measured using the GWTT and

14 longitudinal shear quantified using the OBST. However, only the GWTT was able to detect

15 significant differences in shear resistance between the surfaces. Future work should continue

16 to investigate the strain rate and non-linear load response of surfaces used in equestrian

17 sports. Measurements should be closely tied to horse biomechanics and should include

18 information on the maintenance condition and surface composition. Both the GWTT and the

19 OBST are necessary to adequately characterise all the important functional properties of

20 equine sport surfaces.

\section{Key Words}

23 Torque; shear; arena surface; slip; grip; footing

\section{Nomenclature}

\begin{tabular}{|l|l|l|}
\hline DDFT & Deep digital flexor tendon & \\
\hline$D_{\max }$ & Peak vertical displacement (GWTT) & $(\mathrm{mm})$ \\
\hline GWTT & Glen Withy torque tester & \\
\hline$G R F H_{\max }$ & $\begin{array}{l}\text { Peak longitudinal ground reaction force } \\
(\mathrm{OBST})\end{array}$ & $(\mathrm{kN})$ \\
\hline$G R F V_{\text {mean }}$ & Mean vertical ground reaction force (GWTT) & $(\mathrm{N})$ \\
\hline$G R F V_{\max }$ & Peak vertical ground reaction force (OBST) & $(\mathrm{kN})$ \\
\hline OBST & Orono biomechanical surface tester & \\
\hline SDFT & Superficial digital flexor tendon & \\
\hline
\end{tabular}




\begin{tabular}{|l|l|l|}
\hline SL & Suspensory ligament & \\
\hline Slip & $\begin{array}{l}\text { Horizontal displacement from impact to } \\
G R F V_{\max }(\mathrm{OBST}) \text { calculated from double } \\
\text { integration of GRFH }\end{array}$ & $(\mathrm{mm})$ \\
\hline$T_{\max }$ & Peak torque (GWTT) & $(\mathrm{Nm})$ \\
\hline$T_{\max T}$ & Maximum recorded torque (traction tester) & $(\mathrm{Nm})$ \\
\hline
\end{tabular}

25 
27 The loading of surfaces by horse hooves is complex due to both the range of gaits and speeds and the manoeuvres performed by the horse and the diverse characteristics of the different surfaces. The functional properties of racetrack surfaces have been studied extensively (Peterson, Roepstorff, Thomason, Mahaffey, McIlwraith, 2012; Ratzlaff, Hyde, Hutton, Rathgeber, Balch, 1997; Reiser, Peterson, Mcllwraith, Woodward, 2000; Setterbo, Fyhrie, Hubbard, Upadhyaya, Stover, 2012) but less is known about the characteristics of arena surfaces that are often used for non-racing equestrian sports which involve a more diverse range of athletic activities and hoof surface interaction patterns. In nearly all cases surfaces used for equestrian sports are both highly non-linear and strain rate dependent. For instance, the surface response when executing a canter pirouette in a dressage competition may be quite different to a quick turn during the jump off of a show jumping competition. As the load on the surface increases the typical riding surface increases in stiffness (Reiser et al., 2000) and, in general, the surface will also become stiffer as the load is applied at a higher rate (Setterbo et al., 2012). Since shear resistance of a surface is directly related to the surface stiffness, the grip characteristics are also expected to change with load and loading rate. Thus, there is a need to understand the responses of arena surfaces to both the speed and magnitude of loading, as the stiffness and shear resistance of the surface will influence both the horse's ability to perform and the risk of it receiving an injury.

Shear resistance relates to the frictional forces that are generated between the hoof and the surface and to friction between the particles within the surface (Hobbs et al., 2014). Linear shear resistance affects sliding of the hoof across the surface in a horizontal plane especially during braking phase of stance in straight-line movement. It also affects resistance of the surface when the hoof is in an angled position relative to the ground, as found during push off and sharp turns. Rotational shear resistance affects rotation of the hoof into the surface material, which is also seen during push off and sharp turns. The sliding of the hoof on the surface can either occur between the shoe and the surface, or within the material beneath the hoof depending on the specific characteristics of the surface and the design of the shoe. In addition, the forces generated by the horse's musculotendinous system tend to rotate the hoof into a toe-down orientation within the surface material as the limb generates propulsion

57 (Thomason \& Peterson, 2008). The surface must provide sufficient resistance to the horizontal sliding motion or rotation of the hoof to enable the horse to obtain grip, which 
prevents slipping, tripping or falling (Murray, Walters, Snart, Dyson, Parkin, 2010a) and provides traction for propulsive effort (Crevier-Denoix et al., 2010). Excessive resistance to the horizontal motion or rotation is expected to result in an earlier onset of hoof braking and an increase in the magnitude of the peak stress and loading rate in the limb (Gustås, Johnston, Drevemo, 2006). Reduced horizontal motion of the hoof has been associated with surface hardness (Wilson \& Pardoe, 2001; Orlande, Hobbs, Martin, Owen, Northrop, 2010) and harder surfaces tend to increase the magnitude of higher frequency vibrations during impact and limb loading (Chateau et al., 2009). The high frequency components of the loading are reported to be attenuated mainly by the hoof, and the magnitude of peak stress is gradually damped proximally by the distal limb structures (Lanovaz, Clayton, Watson, 1998; Willemen, Jacobs, Schamhardt, 1999). High frequency loading damages bone and articular cartilage predisposing to the development of osteoarthritis (Folman, Wosk, Voloshin, Liberty, 1986). Insufficient friction and shear resistance can lead to excessive slip and shearing of the top layers of the surface during braking, limiting the traction available for propulsion. Excessive slip during braking causes the horse to reduce stride length as a means of reducing the longitudinal braking force (Chateau et al., 2010) which adversely affects performance. It may also result in rider falls and accidents (Crevier-Denoix et al., 2010; Murray et al., 2010a). Insufficient friction and shear resistance can lead to shearing of the top layers of the surface and result in increased rotation of the hoof into the surface. Excessive slip will then occur during braking, and traction will be lost for propulsion, which is known to increase fetlock joint extension (Crevier-Denoix et al., 2010). Conversely, during midstance maximal fetlock joint extension is reduced which is likely to reduce the storage and release of passive strain energy in the superficial digital flexor tendon (SDFT) and the suspensory ligament (SL) (Crevier-Denoix et al., 2010). The deficit in passive strain energy is proposed to be compensated by a greater active contribution of the deep digital flexor (DDF) muscles to maintain speed (Crevier-Denoix et al., 2010). Early onset of fatigue in the DDF muscle results in greater passive strain of the SDFT which is then at risk of overloading and injury (Butcher et al., 2007). High quality artificial and natural surfaces are needed for equestrian sports in order to provide an appropriate balance between injury reduction and optimal performance of the equine athlete. Shear resistance of the surface is a complex and important factor in this equation and one that has not been adequately evaluated, in part due to a lack of equipment that has been validated to measure shear resistance of arena surfaces. 
Until recently decisions on the design and composition of equine arena surfaces have been based almost entirely on anecdotal observation. This approach has continued in spite of the growing evidence that surfaces can have a major effect on both the performance and the incidence of injury in dressage horses (Murray, Walters, Snart, Dyson, Parkin, 2010b) and eventers (Murray, Singer, Morgan, Proudman, French, 2006) which is similar to the link between surfaces and injuries in racehorses (Oikawa \& Kusunose, 2005; Parkin et al., 2004; Peterson, McIlwraith, Reiser, 2008). Thus the development of reliable equipment that can simulate equine movement and loading patterns to quantify the functional characteristics of arena surfaces in situ is a vital step towards a process for assessment of equine arena surfaces and developing standard methods to ensure consistency across different competition venues. A drop-hammer system, the Orono biomechanical surface tester (OBST) was developed for measuring racetrack properties (Peterson et al., 2008). The OBST has subsequently been modified for use in the evaluation of equine arena surfaces (Northrop, Martin, Holt, Owen, Hobbs, 2014) and for controlled experiments in the UK by the RACES research team (Holt, Northrop, Owen, Martin, Hobbs, 2014). The apparatus was designed to mimic the loading phase of the gait cycle in a galloping horse. It has two axes of motion that allow measurement of both vertical force and linear shear resistance as the simulated hoof lands and is forced across the surface (Peterson \& McIlwraith, 2008). The OBST measures linear shear resistance, but not rotational shear resistance, which may also vary (Nigg \& Yeadon, 1987;

111 Setterbo, Yamaguchi, Hubbard, Upadhyaya, Stover, 2011). The drawback to using the OBST

112 to test arena surfaces is that it is designed to replicate the loads and speeds of a horse's

113 forelimb at the gallop (Peterson et al., 2008), or when landing from a jump, but it is not well

114 suited to the lower strain rates associated with slow gaits and rotational movements, such as 115 the dressage canter pirouette.

117 In human sports an apparatus for measuring rotational traction and friction of turf sports 118 pitches was originally designed in 1975 (Canaway \& Bell, 1986). The studded-boot 119 apparatus, known as a torque tester, is now the internationally accepted device used in a 120 number of sports to ensure safety and performance (Twomey, Otago, Ullah, Finch, 2011). In 1212010 a traction tester was adapted for use on equine surfaces by replacing the football studs 122 with a studded horse shoe (Blundell, Northrop, Owen, Lumsden, 2010). This device was 123 used for comparison in the present study, however, the apparatus is not considered to be 124 representative of the way a horse lands or turns on a surface, due to the low mass, low 125 vertical drop height and the turning procedure used. Concerns also exist related to the 
applicability of the test even for human athletes. In particular, significant variation was reported between operators (Blundell et al. 2010), which has been addressed by providing automatic control of the speed of the turning and positioning of the studded disk (McNitt, Middour, Waddington, 1997; Roche, Loch, Poulter, Zeller, 2008). The modified traction tester measures linear and rotational traction simultaneously (Brosnan, McNitt, Serensits, 2009). However, neither design has been adapted for the speed and loads associated with the equine athlete.

134 Other methods for assessing the horizontal properties of equine surfaces have included cadaver limbs attached to a drag apparatus instrumented with load cells (Clanton, Kobluk,

136 Robinson, Gordon, 1991) and more recently a track testing device that measured linear shear resistance and a shear vane tester that measured shear stress and surface cohesion (Setterbo et al., 2012). The latter of these designs (Setterbo et al., 2012) has been used to make measurements on dirt and synthetic racetracks, but both designs were reported to have limitations in relation to replicating equine locomotion. Shear resistance on turf racetracks is normally measured using a GoingStick (Caple, James, Bartlett, 2012), where a flat blade is pushed into the surface and then rotated about its base to an angle of $45^{\circ}$ to measure the force needed to push and turn the blade (Peterson et al., 2012). A linear relationship between shear resistance using a GoingStick and peak torque resistance using a studded disk apparatus was found on turf sport pitches (Caple et al., 2012). This relationship has only been investigated on turf surfaces which have a relatively homogeneous cross section that is necessary for the health of the turf. This is usually not the case with racing surfaces (Mahaffey, Peterson, McIlwraith, 2012) or with arena surfaces composed of fibre and sand (with or without the addition of wax). In these surfaces a hard pan layer is set up under the shallow top surface that supports the hoof during propulsion or landing. The non-homogeneity of these surfaces makes them unsuitable for evaluation using a penetrometer type device such as the GoingStick for measuring shear resistance.

An appropriate mechanical apparatus for measuring the rotational shear properties of equine sport surfaces is not available. Current methods used in human biomechanics do not adequately represent the hoof-surface interaction and current equine specific measurements do not measure rotational shear. For this reason a new piece of equipment, named the Glen Withy torque tester (GWTT), was designed that was capable of measuring rotational torque whilst under a consistently applied quasi-static vertical load. The device is named after its 
160

161

162

163

164

165

166

167

168

169

170

171

172

173

174

175

176

177

178

179

180

181

182

183

184

185

186

187

188

189

190

191

192

designer which provides the potential for it to become a piece of standardised equipment in the future. This study compares data from the GWTT with data from other equipment used to test arena surfaces (OBST and traction tester) to assess its ability to provide distinct information describing the equine arena surface response. In addition, by using different pieces of equipment, that apply different loading rates, the effect of strain rate dependency on shear resistance can be explored. The aims of the study were to use the GWTT for measuring equine arena surfaces and to compare its results with those from the OBST and traction tester within and between surfaces. Linear and rotational shear resistance may vary for the same surface (Nigg \& Yeadon, 1987), and arena surfaces are reported to be strain rate dependant. It was therefore hypothesised that any relationship between measurements from the OBST compared to the GWTT and traction tester for the same surface, in particular measures of rotational and longitudinal shear, would be non-linear and complex and would not be expected to be well correlated. Also, even if a correlation between these devices was observed on a particular surface it would not necessarily be applicable to other surfaces.

Therefore, the initial investigations using the GWTT and the other devices were performed using two different types of surfaces.

\section{Methods}

The construction and measurements made by the traction tester and a first-generation OBST have been previously described (Blundell et al., 2010; Peterson et al., 2008). In this work, we give construction details of the GWTT, and describe the types of measurement that are made by the traction tester, GWTT, and arena-surface modified OBST. The three devices are shown in Fig. 1.

\subsection{Equipment}

\subsubsection{Glen Withy Torque Tester (GWTT)}

The GWTT is an instrumented hoof design built into a support structure that can carry up to $100 \mathrm{~kg}$ mass and that has suitable attachments for a tractor or similar sized equipment to move it easily. The support structure of the GWTT was based on a vertical central column and horizontal cross member of $75 \mathrm{~mm}$ box section (see Figure 1). The central column houses a $25 \mathrm{~mm}$ diameter main shaft that rotates on ball bearing races (47 mm outer diameter (o.d.)) at the top and bottom of the shaft. In addition, 2 ball bearing thrust races (50 mm o.d. at the top and $100 \mathrm{~mm}$ o.d. at the bottom) carry the vertical thrust force. Attached to the bottom of 
193 the main shaft is a housing that sandwiches a piezoelectric dynamometer (Kistler Instruments

194 Ltd. Hook, Hampshire, UK, model 9271A; model 9272 is the currently available equivalent),

195 through which applied vertical force and dynamic torque are applied and measured

196 respectively. A horseshoe is fixed to the bottom of the housing at the base. At the top of the

197 main shaft is a square fitting drive to which a two-ended handle can be secured when in use

198 to provide complementary torque. The amount of rotational twist is measured by a dial

199 indicator fitted to the square section. The housing of the central column supports adjustable

200 bars on both sides to allow easy attachment and removal of circular masses. A control box to

201 house the instrumentation is also secured to the central column. The horizontal cross member

202 is designed to be attached to the bottom two links of a type 1 three-point tractor implement

203 linkage. Attached to the cross member is a spring loaded linear potentiometer (Novotechnik,

204 Ostfildern, Germany, model TRS 100) with a foot at its base and this measures the vertical

205 displacement of the horseshoe into the surface as torque is applied. An attachment on the

206 column for the top tractor link of the three-point linkage is also provided (see supplementary

207 materials for assembly drawings). Once the GWTT is secured in the three-point-linkage

208 vertical stability can be maintained, but with sufficient slack to prevent resistance at the links

209 during testing which might otherwise influence the torque measurements. To obtain dynamic

210 measurements the equipment is lowered slowly to the ground on the three point linkage, once

211 slack against the links the handle is turned through a measured angle by the same operator

212 and then raised immediately after turning is complete. Typical hoof rotations during

213 locomotion are shown in Fig. 2, which highlights the point in the stance phase most relevant

214 to the operation of the equipment.

215

216 Three different masses were examined as part of the GWTT validation process. The mass of

217 the apparatus was $16 \mathrm{~kg}$, which was used as a baseline measurement. Addition of a $30 \mathrm{~kg}$

218 mass (total $46 \mathrm{~kg}$ ) was selected as being equivalent to the mass used by the traction tester

219 (Blundell et al., 2010). Addition of a $100 \mathrm{~kg}$ mass (total $116 \mathrm{~kg}$ ) was used which provided

220 approximately half the mass of a pony and one fifth the mass of a horse. Three turning angles

$221\left(40^{\circ}, 90^{\circ}, 140^{\circ}\right)$ were selected to give an indication of the effect of turning by different

222 degrees on the variability of the data produced by the apparatus. The minimum angle of $40^{\circ}$

223 was chosen to represent the rotation of the horse's body about a grounded limb, for example

224 during a canter pirouette where the leading hind limb is in contact with the ground for almost

$22580 \%$ of the stride (Burns \& Clayton, 1997). As maximum torque is normally produced prior

226 to shear failure, turning the GWTT through the maximum possible angle ensured that the 
separate events of shear failure and maximum torque were most likely to be captured. While the central column was able to be turned through an angle more than $140^{\circ}$, a maximum angle of $140^{\circ}$ was used. A rotation of the device of $90^{\circ}$ provided an intermediate value. Turning speed was estimated and reproduced through practice and repetition of the same operator.

The voltage signals from the dynamometer were amplified (Kistler Instruments Ltd. Hook, Hampshire, UK, charge amplifier model 5073) and these, together with the linear potentiometer signals were then converted to a digital signal (National Instruments UK, Newbury, Berkshire, UK, A/D converter model NI USB-6210). All were sampled simultaneously for $10 \mathrm{~s}$ at $100 \mathrm{~Hz}$ in Labview (National Instruments UK, Newbury, Berkshire, UK). Peak torque ( $\left.T_{\max }\right)$, peak vertical displacement $\left(D_{\max }\right)$ and mean vertical force $\left(G R F_{\text {mean }}\right)$ were extracted from the digital data acquired using the device.

\subsubsection{Traction Tester}

The traction tester is a simple design that uses a steel rod attached to a circular, screw-on base with a studded horseshoe on the underside of the base (Fig. 1). Three circular, $10 \mathrm{~kg}$ masses each with a central hole are secured to the rod above the base. Two handles at the top of the apparatus allow it to be lifted and dropped. The operator lifted the device to a height of $0.2 \mathrm{~m}$ before releasing it, to allow the horseshoe to embed into the surface. Once the apparatus had been dropped, a torque wrench was applied to the top of the rod and then was rotated until shear failure of the surface occurred. The maximum value recorded $\left(T_{\max T T}\right)$ on the torque wrench prior to failure was tabulated for each trial. The same experienced researcher was used throughout to reduce variability, consistent with general practice (Blundell et. al, 2010).

\subsubsection{Orono Biomechanical Surface Tester (OBST)}

252 The operation of this apparatus has been described previously (Peterson et al., 2008). For 253 these tests the hoof was dropped through a distance of $0.86 \mathrm{~m}$ down the rails which were at 254 an angle of $8^{\circ}$ from the vertical. Temporal data from a tri-axial load cell (Kistler Instruments

255 Ltd. Hook, Hampshire, UK, type 9347C) and string potentiometer (Celesco, Chatsworth, CA, 256 USA, model PT5A) were recorded simultaneously (National Instruments UK, Newbury, 257 Berkshire, UK, A/D converter model NI USB-6210) for 2 s in Labview at $2000 \mathrm{~Hz}$ (National 258 Instruments UK, Newbury, Berkshire, UK). The files were converted to a suitable ASCII 259 format and then imported into Visual 3D. Landing force was determined from the vertical 260 component of force from the tri-axial load cell using a threshold of $50 \mathrm{~N}$ and peak vertical 
261 force from the maximum value recorded $\left(G R F V_{\max }\right)$. Landing speed was derived from the 262 string potentiometer displacement data and the longitudinal component obtained using 263 trigonometry. Slip distance was then measured by double integration of the longitudinal 264 component of force, where the force was divided by mass prior to the first integration and 265 landing speed was used as a constant for the second integration. Slip distance during loading 266 (Slip) was then measured from landing to peak vertical force. The longitudinal force 267 component was rectified and the maximum value identified to obtain peak longitudinal force $268\left(G R F H_{\max }\right)$.

269

\subsection{Initial validation of GWTT measurements}

\subsubsection{Procedure}

272 A calibration measurement of the coefficient of friction of the GWTT shoe on black mild 273 steel plate was carried out in the laboratory using a calibrated 8 camera Qualisys Oqus system 274 capturing data at $100 \mathrm{~Hz}$. Markers were attached at the top and bottom edge of a $1 \mathrm{~m}$ flat 275 black steel plate and four markers were attached to the underside of a shoe made for the GWTT. Trials were captured as the shoe slid down the angled steel plate with the angle of the plate being varied in small increments from trial to trial to provide data that included speeding up, constant velocity and slowing down. Ten tests were recorded with the open end facing up the slope and a further 10 tests with the open end facing down the slope. The angle was varied for each trial. In addition, four repeated measurements of the angle required to initiate movement of the shoe were recorded in four different orientations of the horse shoe; front, back, left, right.

Measurement of the coefficient of friction of the GWTT shoe on black mild steel was carried out in-situ using the GWTT and a flat black mild steel plate with steel grips welded to the underside. This plate was firmly secured into an arena surface prior to testing. The GWTT was loaded with $100 \mathrm{~kg}$ mass, lowered onto the steel plate and rotated slowly through $90^{\circ}$ and the load removed following turning. Eight repeated measurements were recorded.

\subsubsection{Data Analysis}

291 For the laboratory based measurements, markers on the flat plate and the shoe were tracked and exported to Visual 3D. The angle of the plate was determined from the marker coordinates and the shoe velocity during sliding was derived. Average acceleration was

294 calculated over the last third of the slope. The coefficient of friction was determined by 
calculating the tangent of the angle. Static friction mean and standard deviation (s.d.) were tabulated. Linear regression was used to determine the coefficient of friction value at zero acceleration for sliding friction.

298

For in-situ measurements $T_{\max }$ and $G R F_{\text {mean }}$ were extracted from the GWTT and the frictional force calculated from the shoe dimensions. The coefficient of friction was calculated by dividing the frictional force by $G R F_{\text {mean. }}$ Mean and s.d. were calculated and results from the in-situ test were compared to the laboratory sliding friction results.

303

\subsection{In-situ testing of GWTT, OBST and traction tester}

\subsubsection{Procedure}

Two artificial surfaces were used; a waxed sand and fibre surface and a non-waxed sand and fibre surface. Each surface was tested using 5 repeats at 9 locations with each piece of equipment separately (see Fig. 3). The order of testing of additional mass (0, 30 and $100 \mathrm{~kg}$ ) and turn angle $\left(40^{\circ}, 90^{\circ}\right.$ and $\left.140^{\circ}\right)$ was randomised.

310

311 A surface sample was also taken from each location. The top layer of surface was removed 312 and a minimum of $100 \mathrm{~g}$ of sub-surface was placed into a labelled plastic bag and sealed. To evaluate moisture content $100 \mathrm{~g}$ of the surface from each sample was weighed out and placed in a pre-weighed heat-proof tray that was baked in an oven at $38{ }^{\circ} \mathrm{C}$ for $48 \mathrm{~h}$. The samples were then re-weighed and the moisture content determined using ISO/TS 17892-1:2004.

Three temperature loggers (Gemini Data Loggers, Chichester, West Sussex, UK, model

318 Tinytag Talk 2) were utilised in the week prior to data collection. One was placed $100 \mathrm{~mm}$ below the surface of the test track, one was placed on top of the surface, and the third was placed above the surface to measure the air temperature. The loggers were programmed to record temperature every $10 \mathrm{~min}$. The mean temperature \pm standard error in each position was calculated for the week leading up to data acquisition. The measurements of moisture for the unwaxed surface and temperature for the waxed surface are consistent with data reported in the relevant literature (Bridge, Peterson, McIlwaith, Beaumont, 2010; Ratzlaff et al., 1997). However, for consistency both temperature and moisture were measured for both surfaces. 

significance set at $P<.05$. Data were screened for normality using a Kolmogorov-Smirnov test. To identify the most appropriate protocol for use of the GWTT in relation to applied load and turn angle, a 3 (mass) x 3 (turn angle) MANOVA was used with $T_{\max }$ and $D_{\max }$ as dependant variables with Bonferroni post hoc tests on significant variables. To investigate consistency of loading the limits of agreement between applied load and $G R F_{\text {mean }}$ when separated by mass and turn angle were determined (Bland \& Altman, 1999). To evaluate the relationship between measurements 1) on the same surfaces and 2) between surfaces made by each piece of equipment, a partial correlation controlling for significant factors identified in the MANOVA was used and 1) controlling for surface and 2) without controlling for surface. Finally, a MANOVA was used for all measurements to compare the difference between the two surfaces, with mass as a covariate. Stratified bootstrapping (1000 samples) was used on all non-normally distributed measurements when conducting parametric tests.

\section{Results}

344 A typical raw data file is shown in Fig. 4 from the GWTT. Data were normally distributed for $345 D_{\max }, T_{\max }$ and Slip. All other data were not normally distributed. The coefficient of sliding 346 friction determined from the lab-based testing was 0.196 \pm 0.006 (mean \pm C.I.) (see Fig. 5) and for in-situ testing was $0.173 \pm 0.021$ (mean \pm s.d.) for the shoe on black steel plate. The coefficient of static friction was $0.238 \pm 0.018$ (mean \pm s.d.).

The moisture contents for the waxed surface and non-waxed surface were $5.1 \pm 2.11 \%$ and $17.8 \pm 1.68 \%$ respectively (mean \pm s.d.). Air temperature, surface temperature and sub-surface temperature in the week leading up to data collection measured in and above the waxed surface were $19.5 \pm 0.1{ }^{\circ} \mathrm{C}, 22.5 \pm 0.2{ }^{\circ} \mathrm{C}$, and $20.2 \pm 0.1{ }^{\circ} \mathrm{C}$ respectively. Weather conditions were considered to be temperate on the day of testing and there was no rainfall.

Mean \pm s.d. results for $T_{\max }$ and $D_{\max }$ with respect to mass and turn angle for the GWTT, for both surfaces combined, are shown in Table 1. A significant main effect $(\mathrm{P}<.001)$ of mass was found in the model with significant differences for both $T_{\max } \mathrm{F}(2)=582.227, P<.001$ and $D_{\max } \mathrm{F}(2)=6.754, P=.002$. No significant differences were found for turn angle and there was no significant interaction between mass and turn angle. 
362 The limits of agreement between $G R F_{\text {mean }}$ and the applied load separated by mass are shown 363 in Fig. 6 together with the percentage of measurements that fell outside of \pm 1 s.d. limits for 364 each turn angle. The mean difference between measurements was $-94.3 \pm 46.2,-75.0 \pm 106.3$ and $-23.1 \pm 75.5 \mathrm{~N}$ for 0,30 and $100 \mathrm{~kg}$ masses respectively. A turn angle of $40^{\circ}$ was most often outside of the limits of agreement followed by $140^{\circ}$.

The relationship between measurements is shown in Table 2. When controlling for mass, a weak negative relationship was found between $D_{\max }$ from the GWTT and $T_{\max T T}$ from the traction tester $(R=-.257, P=.019)$. A weak positive relationship was found between $D_{\max }$ and Slip $(R=.234, \mathrm{P}=.033)$. No other relationships between variables were found.

Measurements for all equipment (mean \pm s.d.) are shown in Figure 7 separated by surface and for the GWTT also separated by mass. A significant main effect $(P<.001)$ was found for surface with significant differences in $T_{\max } \mathrm{F}(1)=12.38, P=.001, D_{\max } \mathrm{F}(1)=10.57, P=.002$, and $G R F V_{\max } \mathrm{F}(1)=15.37, P<.001$. No other measurements were found to differ significantly between surfaces.

\section{Discussion}

380

This study examined the capability of a newly developed piece of equipment, known as the Glen Withy Torque Tester (GWTT), to measure rotational torque on equestrian arena surfaces. The most appropriate protocols were compared over a range of applied loads and turn angles and measurements made with the GWTT were compared to measurements from existing equipment used to evaluate arena surfaces. It was hypothesised that any relationship between measurements, in particular that between $G R F H_{\max }$, slip and $T_{\max }$, would be nonlinear and complex. When pooling the data a weak, but significant linear relationship was found between the GWTT and OBST, which measure rotational compared to linear shear resistance and where markedly different loads and loading rates are applied to the surface. This relationship weakened when controlling for surface. These findings suggest that the hypothesis might, in part, be cautiously rejected when comparing linear slip to vertical displacement of the GWTT into the surface, providing a sufficient number of data points are compared to account for location specific variability. The lack of correlation between other measurements from the GWTT compared to the OBST supported the hypothesis. 


\subsection{Identification of the most appropriate protocol for the GWTT}

396

397

398

399

400

401

402

403

404

405

406

407

408

409

410

411

412

413

414

415

416

417

418

419

420

421

422

423

424

425

426

427

428

The mass applied to the GWTT had a significant effect on the $T_{\max }$ and $D_{\max }$ readings where a greater mass was associated with higher values. Higher traction values have been measured previously with devices suitable for testing sports surfaces when a greater vertical load was applied due to the greater resistance to movement (Baker, 1991; Brosnan et al., 2009; Goodall, Guillard, Dest, Demars, 2005; McNitt et al., 1997). When evaluating each measured mass for reliability against the applied load, it was found that the minimum amount of bias in measured mass occurred when $100 \mathrm{~kg}$ mass was attached to the GWTT. This may be due to the attachment of the GWTT to a 3 point linkage where the heavier mass was more stable once on the ground and as such it may have been easier to apply a rotational torque without inadvertently altering the vertical force. The difference may also have been influenced by spatial inconsistencies, which occur during the slide of the hoof on the surface during the initial contact of the hoof on the arena. The resulting hoof prints and movement of material are difficult to remove with maintenance, but the effect of the prints is reduced at higher loads since the deeper levels of the surface which are measured at higher loads are not impacted as much as the top surface of the arena.

Turning angle did not have a significant effect on $T_{\max }$ or $D_{\max }$ recorded with the GWTT, but a $90^{\circ}$ turn angle provided the most consistent vertically applied load compared to the other two angles for all masses. For at $40^{\circ}$ angle the mass may not have been as consistently applied, due to the shorter time needed to make the turn before the GWTT was lifted again. At $140^{\circ}$ angle, the operator reported that it was difficult to achieve a consistent purchase on the handle. A lack of control whilst rotating a traction device was responsible for low reliability in measurements during a study by Twomey et al. (2011). This, in conjunction with the angle not representing a particular activity carried out by horses, meant that using a turning angle of $40^{\circ}$ or $90^{\circ}$ was more appropriate. One complete canter pirouette is usually completed in 6-8 strides, which suggests that the body will turn through $45-60^{\circ}$ over an inside hind limb that is grounded for the majority of the turn if the movement is executed correctly (Burns \& Clayton, 1997). Similarly, a show jumping horse is expected to turn as tightly as possible during the jump off round of a class (the jump off is a shorter version of the original course and is to be completed as fast as possible). Crevier-Denoix et al. (2014) recently reported that a pure static rotation of the hoof in the surface rarely occurs, as the hoof also slides transversally and longitudinally throughout turning, which is not replicated by the GWTT. In addition, GWTT does not simulate the loading conditions during propulsion. The 
429 GWTT is rigid, simulating a turn of a planted foot under a quasi-static load, so further work 430 is required to investigate it's applicability to the biomechanics of turning. The results can be 431 considered as promising though with respect to the magnitude of peak torque $\left(T_{\max }\right)$, since 432 they were comparable with those found by Chateau et al. (2013) in horses trotting in circles 433 on different surfaces.

435 The accuracy of the measurements from the GWTT were compared to standard laboratory 436 tests for static and sliding friction of the shoe on black mild steel. The coefficient of static 437 friction for steel on steel with an oxide coating was reported to be 0.27 and for sliding friction 438 with a greasy surface 0.09 - 0.19 (Engineers Handbook, 2006). These values are comparable 439 with the laboratory based test results and in-situ test results obtained in this study, suggesting 440 that the GWTT provides sufficient accuracy of measurement for friction and shear resistance 441 when loaded with a $100 \mathrm{~kg}$ mass.

443 Turning speed was subjectively controlled in the current study. As the surfaces tested are 444 strain rate dependant (Reiser et al., 2000), small differences in turning speed may have influenced measurements from the GWTT. The GWTT has since been instrumented with an angular potentiometer (see supplementary information), which will allow turning speed to be taken into account in future work. This will also allow for a more detailed examination of maximum torque and shear failure events using higher sampling frequencies.

\subsection{Relationships between measurements}

451 The relationship between the vertical displacement of the GWTT $\left(D_{\max }\right)$ and slip measured from the OBST suggests that more slip would be expected on a surface where the top layer deforms more under an applied load. Greater deformation is usually associated with more particle movement as a consequence of large pore spaces and less angularity in sand shape (Bridge, Mahaffey, Peterson, 2014). Moisture content, polymer binder and fibre content are also relevant. The relationship was thought to be weak due to the viscoelastic nature of the surfaces, particularly as the moisture content varied between surfaces and across locations. The surface specific increase in $T_{\max }$ with an increase in $D_{\max }$ suggests that rotational torque increases as the shoe is displaced further into the surface vertically, possibly due to increasing forces from the surrounding substrate (Burn, 2006). This contradicts the relationship found between $D_{\max }$ recorded with the GWTT and $T_{\max T T}$ measured using the traction tester, which suggests that surfaces with greater vertical deformation offer less traction. An explanation 
may relate to the difference in function between the devices. The traction tester tended to be pulled out from the surface, whereas the GWTT tended to "screw down" into the surface. The traction measurement may therefore be indicative of the looseness of the cushion, rather than the shear strength of the surface as a whole. The disputed reliability of the traction tester may also have influenced these results (Twomey et al., 2011). The surface specific relationships found for the OBST show the intrinsic link between the components of force from a dynamic impact and data derived from forces, in this case slip.

The lack of a relationship between other measurements highlights the complexity of arena surface functional properties and their measurement. The need for truly functional measurements of arena surfaces is therefore clearly supported by these results. These surfaces usually have a loose upper layer which allows motion of the hoof early in the loading phase supported by an underlying firm layer. This stratification accentuates the nonlinear character of the materials since the initial stiffness of the surface is very low but it increases with an increase in the load. This increase in stiffness as a function of loading occurs in both vertical and horizontal directions. At the same time the strain rate sensitivity of the loading in shear is characteristic of a porous material where flow of water or wax is highly dependent on the loading rate (Bridge, Peterson, McIlwaith, 2011). This supports the principle that the loading of the surface must represent the rate and load of the hoof for the particular usage of the surface.

\subsection{Comparison of surface behaviour}

Differences between the waxed and non-waxed surfaces were detected by the GWTT and the OBST, but not the traction tester. However, only the GWTT was able to detect significant differences between the surfaces in relation to shear resistance characteristics.

The significantly higher torsional resistance measurements and the significantly lower displacement measurements for the waxed surface when compared with those for the nonwaxed surface (all obtained using the GWTT), indicates that the waxed surface exhibits greater shear resistance than the non-waxed surface. Although not significant, the reduction in slip for the waxed surface also suggests that this surface has more grip. In baseball playing surfaces with higher soil bulk density levels are associated with significantly increased linear and rotational traction (Brosnan et al., 2009), which is thought to be due to a higher soil bulk density causing greater resistance to the movement of the athlete's studs through the profile 
497 (Brosnan et al., 2009). Less surface deformation together with reduced horizontal slip

498 distance was also found by Crevier-Denoix et al. (2013) when comparing horses cantering on

499 turf versus an all-weather waxed surface, but in this case the waxed surface had greater

500 deformation and slip. Chateau et al. (2009) also described an increased duration of the

501 braking phase on all-weather waxed sand compared to crushed sand. The wax component of

502 a surface may therefore be less of a determinant of shear resistance and grip than, for instance

503 the surface density. Surface density did not, however, affect the traction values recorded on

504 synthetic equine surfaces using the traction tester (Holt et al. 2014), although these findings

505 may simply indicate that the equipment is not appropriate for such measurements rather than

506 indicating the lack of a relationship between traction and bulk density.

507

508 The similarity of $G R F H_{\max }$ between surfaces was also somewhat surprising, as greater

509 maximum horizontal force has been measured on crushed sand in comparison to an all-

510 weather waxed track in trotters wearing a dynamometric horseshoe (Robin et al., 2009). In

511 addition, similarity in $G R F H_{\max }$ infers similarity in shear resistance and slip, which was not

512 found. One of the confounding factors in the study of slip and shear resistance was the

513 damping ability of the surface. Crevier-Denoix et al. (2013) reported that waxed surfaces are

514 more effective in damping lower frequency concussion events. As such, indirect

515 measurements of slip may be difficult to interpret alone. Using the horizontal force

516 measurements to determine slip appears to be more sensitive to changes in surface type for

517 the OBST, rather than considering horizontal forces alone.

518

519 When comparing the range of measurements taken from each surface it was also apparent

520 that greater variability was consistently found on the non-waxed surface. Wax is reported to

521 improve surface consistency by reducing the effects of moisture (Bridge, Peterson,

522 McIlwaith, 2012), which was relatively high in the non-waxed surface on the test date. In

523 addition, the fibre type and distribution through the surface may have influenced variability,

524 as longer fibres were evident in the non-waxed surface.

525

526 Using the GWTT it was also possible to calculate the coefficient of sliding friction, which

527 was found to be $0.40 \pm 0.06$ on the waxed surface and $0.37 \pm 0.11$ on a non-waxed surface.

528 These values are lower than the values of 0.585 to 0.741 reported when dragging cadaver

529 hooves across a dirt track (Clanton et al., 1991), and lower than for human sporting activities

530 (Shorten, Hudson, Himmelsbach, 2003). In the study by Clanton et al. (1991) the build up of 
material in front of the hooves may have artificially increased the shear resistance. The requirement for slide in equine activities is expected to be greater than in human activities. Concrete, asphalt and rubber surfaces (smooth and patterned) have been shown to have a static coefficient greater than 0.7, which limits the potential for hoof slip (McClinchey et al. 2004). Gustås et al. (2006) suggested that a high amount of friction during the hoof-surface interaction increases vibration transients, resulting in mechanical stress to the structures of the distal limb and possible injury, thus implying that a surface with a lower coefficient of friction would be more favourable. Harder equine surfaces are commonly reported to have increased grip, which does not support the $G R F V_{\max }$ results compared to the results from the GWTT. However, the $G R F V_{\max }$ values are most likely to have been lower on the waxed surface because the inclusion of a permavoid system in the sub-base has previously been shown to significantly reduce peak vertical force using the OBST (Holt et al., 2014). This highlights the need to use the OBST for measurement of the complete surface in-situ, as many of the current measurement equipments are not capable of detecting differences below the surface that the horse will experience.

\section{Conclusion}

In this study the GWTT was shown to be the only equipment tested capable of identifying and measuring the difference in shear resistance of a waxed surface compared with a nonwaxed surface. This is an important consideration in equestrian sports for facilitating optimal performance without compromising safety. Since the characteristics and performance of arena surfaces are complex, it may be necessary to use more than one piece of equipment to adequately characterise all the important functional properties. Based on the results presented here data from the torque tester did not add significantly to the information provided by the OBST and the GWTT. Future studies should carry out a more extensive evaluation of the functional properties measured by the OBST and the GWTT to explore the complex relationship between linear and rotational shear resistance under different loading conditions.

\section{Acknowledgements}

The authors would like to thank the University of Central Lancashire for funding a studentship and providing the engineering resources needed to undertake this project. The authors would like to thank Myerscough College for providing the test facilities used to carry out in situ testing. 


\section{References}

566 Baker, S. W. (1991). Temporal variation of selected mechanical properties of natural turf 567 football pitches. Journal of Sports Turf Research Institute, 67, 83-92.

568 Bland, J. M. \& Altman, D. G. (1999). Measuring agreement in method comparison studies.

569 Statistical Methods in Medical Research, 8, 135-160.

570 Blundell, E., Northrop, A. J., Owen, A. G., Lumsden, P. J. (2010). The short and long-term 571 changes in mechanical properties of a synthetic equestrian surface. In International Society of 572 Equitation Science Annual Conference. Uppsala, Sweden, 44.

573 Bridge, J. W., Peterson, M. L., Mcllwaith, C. W. \& Beaumont, R. M. (2010). Temperature 574 Effects on Triaxial Shear Strength of Granular Composite Sport Surfaces. Journal of ASTM 575 International, (7) 9, 1 JAI103139.

576 Bridge, J. W., Peterson, M. L. \& McIlwaith, C. W. (2011). Dynamic Strain Rate Response 577 with Changing Temperatures for Wax-Coated Granular Composites, Dynamic Behavior of 578 Materials, Volume 1. Conference Proceedings of the Society for Experimental Mechanics 579 Series, 1, 253-259.

580 Bridge, J. W., Peterson, M. L. \& McIlwaith, C. W. (2012). The Effect of Temperature on the 581 Tangent Modulus of Granular Composite Sport Surfaces. Experimental Techniques, doi: 582 10.1111/j.1747-1567.2012.00851.X

583 Bridge, J. W., Mahaffey, C. A. \& Peterson, M. L. (2014). Analytical test methods used to 584 characterize granular composite sports surface materials. Applied Mechanics and Materials $585440,74-81$.

586 Brosnan, J. T., McNitt, A. S. \& Serensits, T. J. (2009). Effects of varying surface

587 characteristics on the hardness and traction of baseball field playing surfaces. International 588 Turfgrass Society Research Journal, 11, 1-13.

589 Burn, J. F. (2006). Time domain characteristics of hoof-ground interaction at the onset of 590 stance phase. Equine Veterinary Journal, 38, 657-663.

591 Burns, T. E. \& Clayton, H. M. (1997). Comparison of the temporal kinematics of the canter 592 pirouette and collected canter. Equine Veterinary Journal, 23, 58-61.

593 Butcher, M. T., Hermanson, J. W., Ducharme, N.G., Mitchell, L. M., Soderholm, L.V. \& 594 Bertram, J. E. A. (2007). Superficial digital flexor tendon lesions in racehorses as a sequela to 595 muscle fatigue: A preliminary study. Equine Veterinary Journal, 39, 540-545. 
Canaway, P. M. \& Bell, M. J. (1986). Technical note: An apparatus for measuring traction and friction on natural and artificial playing surfaces. The Journal of the Sports Turf Research Institute, 62, 211-214.

599 Caple, M. C. J., James, I. T., \& Bartlett, M. D. (2012). Using the GoingStick to assess pitch 600 quality. Journal of Sports Engineering and Technology 227(2), 83-90.

601 Chateau, H., Robin, D., Falala, S., Pourcelot, P., Valette, J.-P., Ravary, B., Denoix, J.-M. \& 602 Crevier-Deniox, N. (2009). Effects of a synthetic all-weather waxed track versus a crushed 603 sand track on 3D acceleration of the front hoof in three horses trotting at high speed. Equine 604 Veterinary Journal, 41(3), 247-251.

605 Chateau, H., Holden, L., Robin, D., Falala, S., Pourcelot, P., Estroup. P., Denoix, J.-M. \& 606 Crevier-Denoix, N. (2010). Biomechanical analysis of hoof landing and stride parameters in 607 harness trotter horses running on different tracks of a sand beach (from wet to dry) and on an 608 asphalt road. Equine Veterinary Journal, 42(38), 488-495.

610 Chateau H, Camus M, Holden-Douilly L, Falala S, Ravary B, Vergari C, Lepley J, Denoix JM, Pourcelot P \& Crevier-Denoix N. (2013). Kinetics of the forelimb in horses circling on

612 different ground surfaces at the trot. The Veterinary Journal, 198(1), e20-e26. Clanton, C., Kobluk, C., Robinson, R. A. \& Gordon, B. (1991). Monitoring surface conditions of a Thoroughbred racetrack. Journal of the American Veterinary Medical

614 Association, 198, 613-620.

615 Crevier-Denoix, N., Robin, D., Pourcelot, P., Falala, S., Holden, L., Estoup. P., Desquilbet. 616 L., Denoix, J.-M. \& Chateau, H. (2010). Ground reaction force and kinematic analysis of 617 limb loading on two different beach sand tracks in harness trotters. Equine Veterinary 618 Journal Supplement, 38, 544-551.

619 Crevier-Denoix, N., Pourcelot, P., Holden-Douilly, L., Camus, M., Falala, S., Ravary620 Plumioen, B., Vergari, C., Desquilbet. L., \& Chateau, H. (2013). Discrimination of two 621 equine racing surfaces based on forelimb dynamic and hoof kinematic variables at the canter. 622 The Veterinary Journal, 198, e124-e129.

623 Crevier-Denoix, N., Camus, M., Falala, S., Ravary-Plumioen, B., Pauchard, M., Martino, J., 624 Desquilbet, L., Chateau, H. \& Pourcelot, P. (2014). 3D measurement of the displacement of 625 the forelimb hoof during stance in three horses circling at the canter on a competition surface.

626 Computer Methods in Biomechanics and Biomedical Engineering, 17, supplement 1, 142627143.

628 Engineers Handbook (2006). Coefficient of friction. Engineers Handbook. Available at 629 www.engineershandbook.com/Tables/frictioncoefficients.htm, Accessed 25.10.14. 
630 Goodall, S. A., Guillard, K., Dest, W. M. \& Demars, K. R. (2005). Ball response and traction

631 of skinned infields amended with calcined clay at varying soil moisture contents.

632 International Turfgrass Society Research Journal, 10, 1085-1093.

633 Gustås, P., Johnston, C. \& Drevemo, S. (2006). Ground reaction force of hoof deceleration

634 patterns on two different surfaces at the trot. Equine and Comparative Exercise Physiology, 635 3(4), 209-216.

636 Folman, Y., Wosk, J., Voloshin, A. \& Liberty, S. (1986). Cyclic impacts on heel strike: A

637 possible biomechanical factor in the etiology of degenerative disease of the human locomotor 638 system. Archives of Orthopaedic Traumatic Surgery, 104, 363-365.

639 Hobbs, S. J., Northrop, A. J., Mahaffey, C., Martin, J. H., Clayton, H. M., Murray, R.,

640 Roepstorff, L. \& Peterson, M. (2014). Equine Surfaces White Paper. FEI Publication.

641 Available at www.fei.org/fei/about-fei/publications/fei-books Accessed 25.10.14.

642 Holt, D., Northrop, A., Owen, A., Martin, J. \& Hobbs, S. J. (2014). Use of surface testing

643 devices to identify potential risk factors for synthetic equestrian surfaces. Procedia

644 Engineering, 72, 949-954.

645 ISO/TS 17892-1:2004 (2004) Geotechnical investigation and testing - Laboratory testing of

646 soil - Part 1: Determination of water content. Available at

647 www.iso.org/iso/home/store/catalogue_tc/catalogue_detail.htm?csnumber=38514 Accessed

$648 \quad 25.10 .14$.

649 Lanovaz, J. L., Clayton H. M. \& Watson, L. G. (1998). In vitro attenuation of impact shock 650 in equine digits. Equine Veterinary Journal Supplement, 26, 96-102.

651 Mahaffey, C. A., Peterson, M. \& McIlwraith, C. W. (2012). Archetypes in Thoroughbred dirt 652 racetracks regarding track design, clay mineralogy, and climate. Sports Engineering, 15(1), $653 \quad 21-27$.

654 McClinchey, H. L., Thomason, J. J. \& Runciman, R. J. (2004). Grip and slippage of the 655 horse's hoof on solid substrates measured ex Vivo. Biosystems Engineering, 89(4), 485-494. 656 McNitt, A. S., Middour, R. O. \& Waddington, D. V. (1997). Development and evaluation of 657 a method to measure traction on turfgrass surfaces. Journal of Testing and Evaluation, 25, 658 99-107.

659 Murray, J. K., Singer, E. R., Morgan, K. L., Proudman, C. J. \& French, N. P. (2006). The risk 660 of a horse-and-rider partnership falling on the cross-country phase of eventing competitions. 661 Equine Veterinary Journal. 38(2), 158-163. 
662 Murray, R. C., Walters, J. M., Snart, H., Dyson, S. J. \& Parkin, T. D. H. (2010a).

663 Identification of risk factors for lameness in dressage horses. The Veterinary Journal, 184, 664 27-36.

665 Murray, R. C., Walters, J. M., Snart, H., Dyson, S. J. \& Parkin, T. D. H. (2010b). How do

666 features of dressage arenas influence training surface properties which are potentially

667 associated with lameness? The Veterinary Journal, 186, 172-179.

668 Nigg, B. M. \& Yeadon, M. R. (1987). Biomechanical aspects of playing surfaces. Journal of 669 Sports Sciences, 5 117-145.

670 Northrop, A. J., Martin, J. H., Holt, D, Owen A. G. \& Hobbs, S. J. (2014). Development of

671 the equestrian arena surfaces for the 2012 Olympic Games. In Ninth International

672 Conference on Equine Exercise Physiology, Chester, UK.

673 Oikawa, M. \& Kusunose, R. (2005). Fractures sustained by racehorses in Japan during flat

674 racing with special reference to track condition and racing time. The Veterinary Journal 170, 675 369-374.

676 Orlande, O., Hobbs, S. J., Martin, J. H., Owen, A. G. \& Northrop, A. J. (2012) Measuring

677 hoof slip of the leading limb on jump landing over two different equine arena surfaces.

678 Comparative Exercise Physiology, 8(1), 33-39.

679 Parkin, T. D., Clegg, P. D., French, N. P., Proudman, C. J., Riggs, C. M., Singer, E. R., 680 Webbon, P. M. \& Morgan, K. L. (2004). Race- and course-level risk factors for fatal distal 681 limb fracture in racing Thoroughbreds. Equine Veterinary Journal, 36, 521-526.

682 Peterson, M. L. \& McIlwraith, C. W. (2008). Effect of track maintenance on mechanical 683 properties of a dirt racetrack: A preliminary study. Equine Veterinary Journal, 40(6), 602684605.

685 Peterson, M. L., McIlwraith, C. W. \& Reiser, R. F. (2008). Development of a system for the 686 in-situ characterisation of thoroughbred horse racing track surfaces. Biosystems Engineering, 687 101, 260-269.

688 Peterson, M. L., Roepstorff, L., Thomason, J. J., Mahaffey, C. \& McIlwraith, C. W. (2012). 689 Racing Surfaces. White Paper. Available at www.racingsurfaces.org/bulletins.html Accessed $690 \quad 25.10 .14$.

691 Ratzlaff, M. H., Hyde, M. L., Hutton, D. V., Rathgeber, R. A. \& Balch, O. K. (1997).

692 Interrelationships between moisture content of the track, dynamic properties of the track and 693 the locomotor forces exerted by galloping horses. Equine Journal of Veterinary Science, 694 17(1), 35-42. 
695 Reiser, R. F., Peterson, M. L., McIlwraith, C. W. \& Woodward, B. (2000). Simulated effects 696 of racetrack material properties on the vertical loading of the equine forelimb. Sports 697 Engineering, 3, 1-11.

698 Robin, D., Chateau. H., Pacquet, L., Falala, S., Valetter, J.-P., Pourcelot, P., Ravary, B., 699 Denoix, J.-M. \& Crevier-Denoix, N. (2009). Use of a 3D dynamometric horsehoe to assess 700 the effects of an all-weather waxed track and a crushed sand track at high speed trot: 701 Preliminary study. Equine Veterinary Journal, 41(3), 253-256.

702 Roche, M., Loch, D., Poulter, R., Zeller, L. (2008). Measuring the traction profile on 703 sportsfields: Equipment development and testing. Acta Horticulturae, 881, 399-413.

704 Setterbo, J. J., Yamaguchi, A., Hubbard, M., Upadhyaya, S. K. \& Stover, S. M. (2011).

705 Effects of equine racetrack surface type, depth, boundary area, and harrowing on dynamic

706 surface properties measured using a track-testing device in a laboratory setting. Sports 707 Engineering, 14, 119-137.

708 Setterbo, J. J., Fyhrie, P. B., Hubbard, M., Upadhyaya, S. K. \& Stover, S. M. (2012).

709 Dynamic properties of a dirt and a synthetic equine racetrack surface measured by a track710 testing device. Equine Veterinary Journal, 45, 25-30.

711 Shorten, M., Hudson, B. \& Himmelsbach, J. (2003). Shoe-surface traction of conventional 712 and in-filled synthetic turf football surfaces. In XIX International Congress on Biomechanics

713 Available at: www.brock-international.com/docs/Shorten\%20-

714 \%20Traction\%20study\%2050mm\%20turf\%20.pdf. Accessed 25.10.14.

715 Thomason, J. J. \& Peterson, M. L. (2008). Biomechanical and mechanical investigations off 716 the hoof-track interface in racing horses. Veterinary Clinics Equine Practice, 24, 53-77.

717 Twomey, D. M., Otago, L., Ullah, S., Finch, C. F. (2011). Reliability of equipment for 718 measuring the ground hardness and traction. Journal of Sports Engineering and Technology, 719 225, 131-137.

720 Willemen, M. A., Jacobs, M. W. H. \& Schamhardt, H. C. (1999). In vitro transmission and 721 attenuation of impact vibrations in the distal forelimb. Equine Veterinary Journal 722 Supplement, 30, 245-248.

723 Wilson, A.M. \& Pardoe, C.H. (2001). Modification of a force plate system for equine gait 724 analysis on hard road surfaces: A technical note. Equine Veterinary Journal Supplement, 33, 725 67-69. 
Fig. 1: Photograph of: a) the Glen Withy torque tester (GWTT), b) the Orono biomechanical surface tester (OBST) and c) the traction tester.

748

Fig.2: Typical rotational (R) and longitudinal (L) motions of the hoof during the hoofsurface interaction viewed laterally a)

a) footstrike, b) secondary impact, c) breakover where pitch rotation and longitudinal sliding occurs. Frontal and solar views of d) roll rotation, and e) yaw rotation which is most likely to occur during turning and are usually accompanied by longitudinal and/or medio-lateral sliding. The GWTT replicates motion and torque as shown in e).

755

Fig. 3: Plan of the data collection area used to test each of the two surfaces. Each mass and each turn angle were tested at one of the locations. The order was randomised. The testing areas were marked using flags and were $3 \mathrm{~m} \times 4 \mathrm{~m}$ in size.

Fig. 4: A typical graph from the GWTT. The graph illustrates signals for $G_{R F}$ mean (the average of vertical GRF values over the time illustrated $(\mathrm{kN})), D_{\max } \times 10(\mathrm{~mm}), T_{\max }$ (Nm).

Fig. 5: Results of laboratory sliding friction tests showing the coefficient of friction value 765 for the shoe on black mild steel intersection of the $\mathrm{x}$-axis at $0.196 \pm 0.06$ (mean \pm C.I.). 
766 Fig. 6: Bland and Altman (1999) plot of the limits of agreement between $G_{R} F_{\text {mean }}$ from

767 the GWTT and the load applied ((machine mass + applied mass) x gravity) (N), a) 16 +

$768 \quad 0 \mathrm{~kg}$ applied load, b) $16+30$ applied load, c) $16+100 \mathrm{~kg}$ applied load. The dotted

769 horizontal lines show the limits of agreement at 1 standard deviation from the mean.

770 Data points outside of the dotted lines may be considered as inconsistencies in vertical

771 loading of the GWTT.

772

773 Fig. 7: Measured differences between surfaces for the GWTT: $T_{\max }(\mathrm{Nm}), \boldsymbol{D}_{\max } \times 10$

774 (mm); the OBST: Slip (mm), GRFH $H_{\max }(\mathrm{kN}), G R F V_{\max }(\mathrm{kN})$; and the traction tester:

$775 \boldsymbol{T}_{\max T T}(\mathrm{Nm})$. Error bars represent the standard deviation. * Significant differences

$776(P<.05)$ were found for $T_{\max }$ and $D_{\max }$ and $G R F V_{\max }$. 